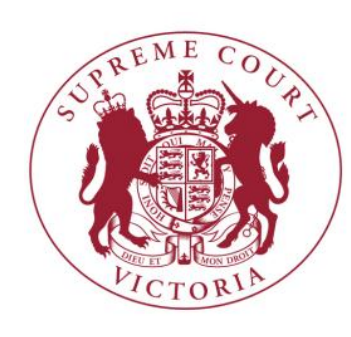

\title{
EXPERT CONFERENCES IN THE KILMORE EAST BUSHFIRE PROCEEDING
}

\author{
SIMON MCKENZIE
}

This paper, the second in a series on the management of expert evidence during the Kilmore East bushfire proceeding, considers the use of expert conferences. Most of the expert evidence in the proceeding went through this process, and the scale of the conferences and extent of their use was a distinctive aspect of the proceeding. This paper is based on material from interviews with some of the judges, barristers, solicitors and experts who were involved in the proceeding, and explores their experience regarding the use of expert conferences in this case. They agreed that the expert conferences and the production of joint reports was a useful exercise. The joint reports provided a summary of the lengthy and complex expert evidence, and gave a clearer picture of the issues that remained in dispute between the experts. The experts also found the conferences valuable, permitting them to have robust and technical discussions about the evidence. The role of the Associate Justice as a moderator in the larger conferences was seen as very helpful, even essential. This is not to say all the participants were completely satisfied by how the procedure was adopted. The paper shows that separating experts into conferences covering different areas of expertise can be difficult to get right, and also the importance of the Court properly consulting with the parties if a requirement for further testing emerges from the expert conferences. It suggests that experts were sometimes adversarial and positional during the conferences when the moderator was not present, which indicates that care should be taken to ensure the experts properly understand their role in the trial process. Nevertheless, the use of expert conferences was a success and the experience in the proceeding is testament to the procedure's benefits.

\footnotetext{
${ }^{*}$ BA, LLB (Hons) (Tas); Senior Fellow (Melbourne Law Masters) and PhD Candidate at the University of Melbourne. The support of Justice Rita Zammit and Justice Jack Forrest was invaluable in carrying out this research project. In addition, the assistance and advice of Gary Cazalet at the University of Melbourne as well as Stuart Moran and Katrina Chow at the Supreme Court of Victoria are gratefully acknowledged. The Supreme Court of Victoria funded this research.
}

This paper was published on 13 April 2016. 


\section{CONTENTS}

I. Introduction .2

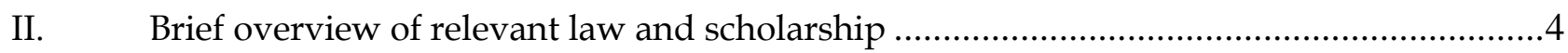

III. The rulings on expert conferences in the Kilmore East bushfire proceeding ......................7

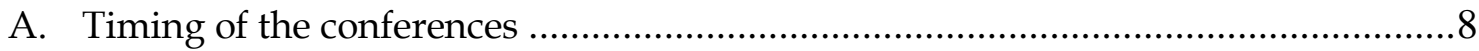

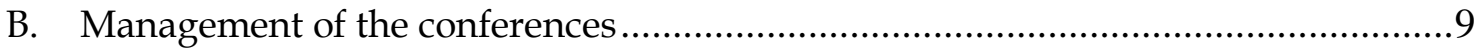

C. Use of questions in conferences and quarantining of experts .............................13

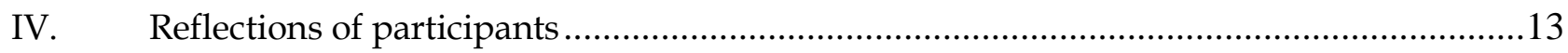

A. Did the expert conferences and joint reports help the proceeding? .......................14

B. Involvement of a Judicial Officer as a moderator ...............................................19

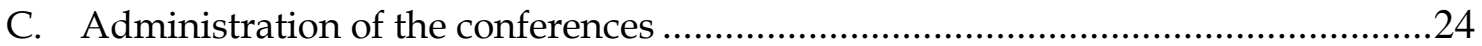

D. Impact of personalities and attitude of experts............................................... 31

E. Quarantining of experts and relationship between the experts and the parties......35

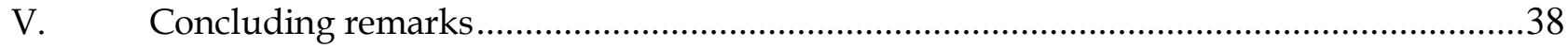

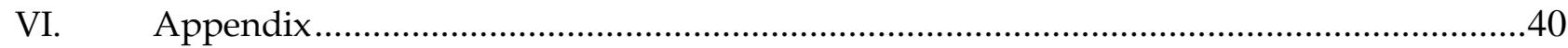

A. Section one: view from Victorian bench................................................................ 40

1. General comments on expert conferences......................................40

2. Quarantining of experts............................................................

3. Need for independent chair or moderator in conferences ..................42

B. Section Two: Methodology.....

\section{INTRODUCTION}

One of the most widely used of the new procedures for the management of expert evidence are expert conferences (otherwise known as conclaves). ${ }^{1}$ An expert conference gathers the experts who are to give evidence in a proceeding, prior to the commencement of the trial, to discuss their evidence and produce a joint report. The joint report sets out the areas of agreement and disagreement between them. The vast majority of the expert evidence given in Matthews $v$ SPI Electricity Pty Ltd (the 'Kilmore East bushfire proceeding') went through this process. ${ }^{2}$ The scale

\footnotetext{
1 The popularity of expert conferences is clear from the literature summarised in the first section of the paper.

${ }^{2}$ For more detail on the factual basis for the case see the first paper in this series, Pre-Trial Management of Expert Evidence in the Kilmore East bushfire proceeding, or Matthews v AusNet Electricity Services Pty Ltd [2014] VSC 663 (23 December 2014), [1]-[9].
} 
of the expert conferences and the extent of their use was a distinctive aspect of the proceeding. At the conclusion of the trial, 40 experts had been called to give evidence, and there had been many expert conferences. These conferences involved between two and nine experts. This paper explores the experience of some of the participants in the expert conferences in the Kilmore East bushfire proceeding.

The material for this paper was gathered in interviews conducted with a small number of the participants in the trial. Capturing the reflections of these participants ensures that there will be a record of how the expert conferences were run, and shows some of the expectations, concerns and conclusions of the judges, lawyers and experts. It provides an opportunity to identify some features that make conferences more, or less, likely to be successful. Before addressing this, however, it is necessary to explain the procedure adopted for the management of the conferences in the Kilmore East bushfire proceeding. The first section of the paper provides a brief and limited overview of the legislative framework as well as the view of expert conferences from the literature, including from Law Reform Commissions, practitioners and academics. It then sets out the rulings of the trial judge, Justice Jack Forrest, regarding the expert conferences, explaining his rationale for the timing of the conferences, which experts should participate in each conference, and why he delegated the administration and moderations of the expert conferences to an associate justice, Associate Justice Rita Zammit. This sets the framework for the reflections of the lawyers and experts.

The record of the participants' experiences were gathered in interviews with Justice Forrest and Associate Justice Zammit, as well as two barristers, two solicitors and two experts. From these interviews, it is clear that most of the participants were convinced that expert conferences were a valuable tool that improved the hearing of expert evidence. This was particularly the case for the legal practitioners, who (with one exception) said that the summary of expert evidence provided by the joint reports was invaluable for their preparation for trial. There were, however, differing views on the merits of the approach taken by the Court to the composition of each conference, the use of an Associate Justice as moderator, and the quarantining of experts during the conferences. It identifies a number of issues that the Court should consider when using the procedure in the future.

The paper also has an Appendix, split into two sections, that contains some additional information that is relevant to this paper. In order to provide a sense of the range of views held by judges of the Court, the first section outlines the opinion of a number of other Victorian Supreme court 
judges about expert conferences. The second section sets out the methodology used in the interviews with the participants in the proceeding, as well as acknowledging some of the limitations of this research.

\section{BRIEF OVERVIEW OF RELEVANT LAW AND SCHOLARSHIP}

Expert conferences are a well-established tool in Australia for the pre-trial management of experts. They provide an opportunity for the experts to meet and prepare joint reports that summarise for the Court the areas in which they agree and disagree. There has been much written about their effectiveness and potential to substantially improve the capacity of the Court to reach just outcomes efficiently. A few examples will suffice. Justice Peter Heerey of the Federal Court explained that:

I have found the court-directed conference a particularly useful exercise with accounting evidence. A conference can produce from a bewildering barrage of figures a concise statement as to the underlying concepts or assumptions which are really at issue. ${ }^{3}$

Neil Young QC said that expert conferences have "been a very effective way of identifying and explaining the points of agreement and disagreement between the experts." ${ }^{4} \mathrm{He}$ said the joint reports produced by the conferences had "by identifying and narrowing the areas of disagreement, [...] [laid] the groundwork for oral evidence that is more focused and likely to be less protracted." 5 The Irish Law Reform Commission said that experts may be more willing to make compromises and concessions in a conference rather than during cross-examination because "the expert would feel under less pressure to defend his viewpoint if it not being discussed in terms of direct conflict with the other side." 6

In Victoria, the Civil Procedure Act 2010 ('the Act') gives the Court broad powers to give directions to experts regarding pre-trial conferences and joint expert reports. This enables the Court to order the experts meet and prepare joint reports prior to trial. Section $65 \mathrm{I}$ of the Act provides that:

1) A court may direct expert witnesses in a proceeding -

a) to hold a conference of experts; or

\footnotetext{
${ }^{3}$ Justice Peter Heerey, 'Expert Evidence: the Australian Experience" (Paper delivered to the WIPO AsiaPacific Colloquium, New Delhi, 6 February 2002) 94.

${ }^{4}$ Neil J Young QC, 'Expert Witnesses: On the Stand or in the Hot Tub - How, When and Why?' (Paper presented to the Commercial Court Seminar, 27 October 2010) [16].

${ }^{5}$ Ibid.

${ }^{6}$ Ireland Law Reform Commission, Consultation Paper - Expert Evidence, (2008) CP52-2008, 5.103.
} 
b) to prepare a joint experts report; or

c) to hold a conference and prepare a joint experts report.

2) The court may direct that a conference of experts be held with or without the attendance of all or any of the following -

a) The parties to the proceeding; or

b) The legal practitioners of the parties; or

c) An independent facilitator.

3) A direction to prepare a joint experts report may include but is not limited to the following -

a) That the joint experts report specifies -

i. The matters agreed and not agreed by the experts; and

ii. The reasons for any agreement or disagreement;

b) The issues to be dealt with in the joint experts report by the expert witnesses;

c) The facts, the assumptions of fact, on which the joint experts report is based.

4) A direction may be -

a) General or in relation to specified issues;

b) Given at any time in a proceeding, including before or after the expert witnesses have prepared or given reports.

The relevant Explanatory Memorandum explained that the provisions would enable the "real issues in the dispute between experts to be identified and narrowed from an early stage of the proceeding." 7

Despite their wide usage, expert conferences are not appropriate for every case, and they do carry some risks. The New South Wales Law Reform Commission (NSWLRC) emphasised that the appropriate approach for the management of the expert conference would depend on the particular facts of the case. While some cases could require lawyers be present, or require a detailed agenda or an independent chair, these measures would not always be necessary. ${ }^{8}$ The NSWLRC recommended courts have flexibility to make orders suitable for particular cases, with the possibility of developing rules or practice directions relating to categories of cases. ${ }^{9}$ It also noted some of the risks with pre-trial conferences between experts:

[...] in some circumstances, the effectiveness of such conferences may be compromised. Hostility between experts might undermine real communication, more senior or experienced experts may dominate and intimidate more junior colleagues, and the conference may be unsuccessful where one

\footnotetext{
${ }^{7}$ Explanatory Memorandum, Civil Procedure Amendment Bill 2012 (Vic).

${ }^{8}$ New South Wales Law Reform Commission, Expert Witnesses, Report No 109 (2005), 6.43.

${ }^{9}$ Ibid 6.44 .
} 
or more of the experts are uncertain about their role as expert witnesses, or about the nature and purpose of the conference. ${ }^{10}$

Gary Edmond points out that the rationale of expert conferences appear to be based on untested assumptions about the relationship between scientific evidence and litigation:

\begin{abstract}
Expert conferences [...] are predicated on the belief that litigation accentuates disagreement. Implicitly, experts released from substantive legal and procedural constraints will be able to broker agreement (or limit the extent of disagreement). This assumes that much expert disagreement is the result of communication problems, distortion caused by legal practices or the restricted orientations encouraged by the commitments of clients. We should not forget, however, that there is considerable scientific controversy beyond legal and regulatory fora. In addition, those few cases that eventually get to trial - the 'tip of the iceberg' that are not settled or abandoned - often involve disputes in areas presented as uncertain or controversial. Can we expect expert meetings to expose or satisfactorily resolve what cross-examination, an oath, or duty, and extra-legal processes often cannot?11
\end{abstract}

There are some cases where courts have decided against holding expert conferences, and these decisions are revealing. For example, in Broadman $v$ South Eastern System Area Health Service ${ }^{12}$ Studdert J refused to order a joint conference of four medical experts because there was a "clear firm and considered divergence of opinion between the experts" on the central medical and factual issues in the case. ${ }^{13}$ In a later case, Studdert J refused to order a conference when there was no reasonable expectation it would result in any agreement on issues for consideration and would involve considerable expense. ${ }^{14}$

The Victorian Law Reform Commission's Civil Justice Report considered a number of submissions on the impact of expert conferences and ways to make them more effective. ${ }^{15}$ Some of the submissions were particularly interesting:

- One submission ${ }^{16}$ suggested that it be compulsory that a court-appointed facilitator participate in pre-trial conferences of experts with the purposes and form of the conference

\footnotetext{
${ }^{10}$ Ibid 6.41. Also see Mia Louise Livingstone, 'Have we fired the 'hired gun'? A critique of expert evidence reform in Australia and the United Kingdom' (2008) 18 JJA 39, 55-6.

11 Gary Edmond, 'After Objectivity: Expert Evidence and Procedural Reform', (2003) 25 Sydney Law Review $131,150$.

12 [2001] NSWSC 930.

${ }^{13}$ Ibid [30].

14 Spasovic v Sydney Adventist Hospital [2002] NSWSC 164.

15 Victorian Law Reform Commission, Civil Justice Review: Report (2008), 508-510.

16 This was only identified in the VLRC Commission Report as 'The Group Submission'.
} 
clearly identified. ${ }^{17}$ The purpose of the facilitator would be "to facilitate meetings between experts and ensure that the process of preparing a joint expert report to the Court identifying the issues which remain contested occurs." 18

- This submission also proposed that 'standard protocols' be adopted regarding who attends the conferences and who was responsible for preparing the first draft of the joint report. ${ }^{19}$

- The Forensic Accounting Group indicated a concern that the "lack of consistency and timeliness" in the application of conferencing provisions was problematic. They instead preferred that a conference be called as soon as opposing parties proposed to call experts and those experts have had sufficient time to form preliminary views on the evidence. ${ }^{20}$

Mia Livingstone was generally supportive of joint conferences, but said they have the potential to increase time, cost and delay. She explained:

$\ldots$ if the parties oppose a joint conference, the procedure can increase the time, cost and delay involved with litigation, particularly because the court must read the expert reports closely to determine whether or not a joint conference would yield any 'utility'. Joint conferences themselves can be very costly, which is often submitted to oppose a joint conference. Even when a joint conference has occurred the parties may apply to adduce further expert evidence, although they are unlikely to succeed in the absence of unusual circumstances. ${ }^{21}$

Justice McClennan of the New South Wales Supreme Court, while being very supportive of the use of expert conferences, has found that two main problems can arise. First, some experts have a tendency to meet but not agree; and second, the withdrawal or modification of part of an agreed joint report after the expert has discussed the matter with the client's lawyer. ${ }^{22}$

\section{THE RULINGS ON EXPERT CONFERENCES IN THE KILMORE EAST BUSHFIRE PROCEEDING}

Justice Forrest had to make a number of decisions about the management of the expert conferences in the Kilmore East bushfire proceeding. When should the conferences be held? How

\footnotetext{
17 Victorian Law Reform Commission, Civil Justice Review: Report (2008), 509.

18 Ibid.

${ }^{19} \mathrm{Ibid}$.

${ }^{20}$ Ibid.

${ }^{21}$ Mia Louise Livingstone, 'Have we fired the 'hired gun'? A critique of expert evidence reform in Australia and the United Kingdom' (2008) 18 JJA 39, 57 (citations omitted).

22 Justice Peter McClennan, Expert Evidence - The Experience of the Land and Environment Court of New South Wales, presented at the XIX Biennial Lawasia Conference 2005, Gold Coast, 20-24 March 2005, p. 6.
} 
should the experts be grouped for the conferences? How should they be managed, particularly in the larger conferences of up to nine experts? How could the experts be encouraged to produce material that would be useful in the concurrent evidence sessions? Given the number of experts and the importance of their evidence to the trial, these rulings had the potential to have a profound impact on the proceeding. Justice Forrest addressed these issues in three rulings: the first concerned the timing of the conferences; the second was a ruling on the management of the conferences; and the third decided that the experts should provide brief answers to assist the Court during the concurrent evidence session. These rulings show what Justice Forrest expected the expert conferences to achieve. They are a starting point for assessing the experience of the participants to analyse whether the predictions made by his Honour stand up to scrutiny.

\section{A. Timing of the conferences}

Justice Forrest had to decide whether the experts' conferences should be held before or after the final mediation before trial. The defendants had objected to holding the conferences before this mediation, arguing that it was an unnecessary expense as the issues of agreement and disagreement could be figured out by an exchange of expert reports prior to the mediation. ${ }^{23}$ His Honour did not accept this submission, identifying five reasons why holding the conferences prior to this mediation was preferable:

1. It would promote the "just, efficient, timely and cost-effective resolution of the real issues in dispute" by identifying these issues as early as possible, and increasing the chances of success at mediation. ${ }^{24}$

2. Once the experts have committed their thoughts to paper, it is "highly desirable they meet in a lawyer-free environment" to sort out the issues upon which they agree and disagree. His Honour observed that sometimes this produced a consensus that was not apparent in the original reports. ${ }^{25}$

3. There is a "distinct positive" to conducting a mediation where there have been joint reports setting out areas of agreement and disagreement between experts rather than letting the

\footnotetext{
${ }^{23}$ [2011] VSC 613 [14].

24 Ibid [15].

${ }^{25}$ Ibid [16].
} 
"lawyers debate what the experts mean or do not mean in their reports". His Honour said that this could only "enhance the prospects of a successful mediation." 26

4. His Honour rejected the argument of the defendants that the exchange of reports was a satisfactory alternative to holding conferences. He explained that "the exercise would merely cause a flurry of lawyer-inspired reports which, if anything, may make the prospect of agreement on issues less likely". ${ }^{27}$

5. The potential for additional costs in the context of the case were not significant. The trial was already going to be very expensive, and the potential damages award could be enormous; as such, his Honour held that concerns about the expense of the conferences could be put to one side..$^{28}$

\section{B. Management of the conferences}

One of the difficulties the Court faced was determining how to group the experts into different conferences. The parties had divergent views on whether the expert witnesses should be required to "participate in discrete sub-issue conclaves or whether the conclave should consist of a larger group of experts." 29 Six general topics of expert evidence were agreed: fire ignition, conductor break, asset management, prescribed burning, fire suppression, and warning. Despite agreement on these topics, the parties differed on the appropriate model for the conferences. The plaintiff argued that the conferences should take place within the six general topics, with one conference involving as many as 11 experts. In contrast, the model proposed by the first defendant was more detailed, and involved specific issue-by-issue conferences and was expected to require fourteen separate conferences. The difference this would make is evident when considering how the plaintiff divided up the general topic of 'conductor break'. This general topic was divided up into six separate conferences:

1. Conductor failure:

a) What were the various fracture types (e.g. fatigue, ductile)?

b) What features did the fractures exhibit?

c) What was the sequence in which the fractures finally failed?

2. Role of lightning:

\footnotetext{
${ }^{26}$ Ibid [17].

27 Ibid [18].

28 Ibid [19].

${ }^{29}$ Ruling No 10 [2012] VSC 379, [2].
} 
a) Presence of lightning strike; and

b) Potential damage caused by a lightning strike.

3. Impact of loads on fractures (role of ill-seated helical termination and absence of vibration dampers):

a) quantitative analysis

i. by reference to tests undertaken metallurgical analysis of cause(s) of the failures including explanation of the various features of the fracture surfaces; and

b) qualitative analysis

i. analysis of likely role of ill-seating and absence of dampers on the fractures by reference to research and other experience.

4. Quantification of loads/stresses:

a) finite element modelling;

b) field test;

c) physical model; and

d) research based calculations.

5. Quantitative analysis of appropriate line design and construction based on industry practice.

6. Role (if any) of $\mathrm{OCR}^{30}$ settings on fire ignition:

a) quantitative analysis (Kilmore East fire);

i. as to possible OCR settings; and

ii. as to their possible impact on likelihood of fire ignition.

b) quantitative analysis (hypothetical fire); and

i. explanation of other experiments in which the impact of OCR settings on fire ignition was investigated.

c) qualitative analysis;

i. purpose of an OCR; and

ii. OCR settings industry practice. ${ }^{31}$

As can be seen, the model proposed by the first defendant allowed for conferences that were substantially more specific, rather than one very large conference covering all of the above topics.

Justice Forrest considered the defendant's approach to be the preferable one. This was despite the fact it would "result in double the number of conclaves and be challenging administratively". ${ }^{32} \mathrm{He}$

30 OCR stands for Oil Circuit Recloser. They are "one of the primary equipments used on distribution feeders to manage overcurrents caused by distribution line faults with a minimum level of supply distribution to consumer": Grahame Holmes, Independent Expert Report on Automatic Circuit Reclosers (ACR) for Single Wire Earth Return (SWER) distribution lines, submitted to the Powerline BushFire Safety Taskforce of Victoria, 15 September 2011, 1.

31 Ibid [5].

${ }^{32}$ Ibid [6]. 
was careful to point out that given the administrative complexity, the model should have a degree of flexibility in its implementation. ${ }^{33}$ He identified a number of reasons why the more complex model was preferable:

1. If each conference dealt with a specific issue there would be "no question about the expertise of the particular witnesses" responsible for authoring the joint report. ${ }^{34}$ His Honour was concerned that if the plaintiff's model was accepted, it had the potential to:

...lead to the production of a joint report where there are issues about the capacity of the authors to express the opinion contained in the report. [...] The suggestion that parts of the report be signed off by only those experts with expertise in the relevant field has little, if any, attraction. ${ }^{35}$

2. It was consistent with an earlier direction that the trial not become a "battle of numbers" between experts. His Honour explained that his "clear indication to the parties was not to engage a bevy of experts and rely upon weight of numbers to get them over the line." $36 \mathrm{He}$ was particularly concerned that under the plaintiff's model, there would be one conference of experts with five expert witnesses engaged by the plaintiff, and only one from the first defendant. ${ }^{37}$ In contrast, the first defendant's model did not lead to the same potential imbalance in any particular conference. ${ }^{38}$

3. The provision of joint reports on specific and discrete issues would hopefully "refine the issues and [have] a greater prospect of leading to clearer identification of the issues that are in dispute and those that are not." 39

4. There would be scope to expand the conferences if the experts considered that it would be helpful. Justice Forrest determined that he would have a judicial officer available to the parties and the experts in the weeks prior to the conferences to help resolve any issues regarding the appropriate procedure. ${ }^{40}$

\footnotetext{
${ }^{33}$ Ibid.

${ }^{34}$ Ibid [7].

35 Ibid.

${ }^{36}$ Ibid [8].

${ }^{37}$ Ibid.

${ }^{38}$ Ibid.

${ }^{39}$ Ibid [9].

${ }^{40}$ Ibid [10].
} 
5. The provision of joint reports using the first defendant's model would not determine the composition of concurrent evidence sessions at trial. His Honour noted that it might be considered appropriate to hold concurrent evidence sessions involving experts from more than one conference. ${ }^{41}$

6. He said that the submissions of the plaintiff misunderstood the role of the expert and that of the Court:

This is not a trial by expert. It is for the Court to determine the issues having regard to all the evidence whatever the source. If the expert evidence, or for that matter the evidence generally, emerges in a piecemeal fashion then that is a problem Courts regularly meet and resolve. ${ }^{42}$

Justice Forrest referred the remaining questions relating to the operation of the conferences to Associate Justice Zammit. ${ }^{43}$ The issues his Honour said should be determined through discussions with the relevant experts and Associate Justice Zammit included:

- whether the conferences should be assisted by a moderator (who would be Associate Justice Zammit) ${ }^{44}$;

- whether there should be a scribe to record the conferences; 45 and

- whether the experts should participate in the conferences via video link, or in person.46

His Honour was sceptical about the worth of a list of questions being provided to the experts, but thought that an agenda to guide discussions would be helpful at "the experts keeping on track". 47

Was this division into the issues-based conferences helpful? The interviews suggest that the division of the experts into the different conferences had mixed effects: although it ensured that only experts of like expertise were in conference together, it also meant that evidentiary problems to which there were simple solutions from other areas of expertise were magnified. For example, engineers that had substantial industry experience could quickly dismiss some of the theories of the physicists due to their knowledge of industry practice, and vice versa. It shows the complexity

\footnotetext{
41 Ibid [11].

42 Ibid [12].

${ }^{43}$ Ibid [13-14].

${ }^{44}$ Ibid [15].

${ }^{45}$ Ibid [16].

46 Ibid [17].

${ }^{47}$ Ibid [19-20].
} 
and necessary artificiality of any decision to divide up experts into different categories: it is necessary to draw a line somewhere, and there will be benefits and drawbacks to each grouping. The other important aspect of this ruling was the appointment of the Associate Judge to manage the operation of the conferences. This proved to be critical, particularly in the larger conferences.

\section{Use of questions in conferences and quarantining of experts}

Justice Forrest made two further interventions to attempt to ensure that the results from the expert conferences were useful to the Court. He set a series of questions that the expert witnesses in conferences 1, 3 and 4 were required to answer. The questions were formulated with the assistance of the assessors 48 and in consultation with the parties. ${ }^{49}$ The experts were asked to provide "brief preliminary responses" to the questions, limited to one paragraph.50 His Honour intended the questions to "serve as a guide to the evidence adduced" during the concurrent evidence session, and to give him a "sense of the lay of the land" in advance of this session. ${ }^{51}$ Justice Forrest explained that these responses were only preliminary, and would not preclude the experts from discussing other matters of relevance to the failure of the conductor. ${ }^{52}$ In addition, the experts were precluded from communicating with the parties or the parties' solicitors while the conferences were occurring, with one exception allowing the parties to consult with the experts prior to the concurrent evidence session. ${ }^{53}$

\section{REFLECTIONS OF PARTICIPANTS}

As has been seen, the rulings by Justice Forrest were intended to improve the effectiveness and probative value of the expert conferences. He thought the production of joint reports would narrow the issues in dispute, and help the court focus on those that were the most important. Moreover, he thought the joint reports would provide a much better groundwork for the concurrent evidence sessions (and before that, the pre-trial mediation) than the exchange of expert reports. He also said that allowing the experts to meet without lawyers present would make it easier for them to reach agreement. He divided the experts into smaller groups for the conferences to try to ensure those in a single conference had similar expertise. He decided against managing

\footnotetext{
48 Justice Forrest appointed assessors to assist him with the most complex expert evidence material. The fourth paper in this series sets out how the assessors were used as well as what the participants in the proceeding thought about their usefulness to the proceeding.

${ }^{49}$ Ruling No 32 [2013] VSC 630, [15].

${ }^{50}$ Ibid [17-18].

${ }^{51}$ Ibid [17].

52 Ibid [18].

${ }^{53}$ Ibid [19-20].
} 
the administrative issues of the conferences himself, and instead allocated that responsibility to Associate Justice Zammit. She acted as a moderator in some of the larger expert conferences, expecting that this would increase the efficiency of these conferences. It was also thought that giving the experts a list of questions to answer at the conclusion of the conference would make it easier to understand how they agreed and disagreed. Finally, Justice Forrest sought to minimise the influence of legal practitioners by preventing them from communicating with the experts for the duration of the conference.

The interviews of participants in the proceeding, conducted after the conclusion of the trial, gives an indication of usefulness of Justice Forrest's approach. These interviews focussed on the following five issues:

1. the efficacy of the expert conferences and joint reports, and in particular whether they were helpful in reducing the number of issues in dispute;

2. the effect of the involvement of a Judicial Officer as a moderator in expert conferences;

3. whether the administration of the conferences was appropriate;

4. the impact of the personalities and attitudes of the experts in the expert conferences; and

5. the effect of the quarantining of experts on the relationship between the experts and the parties.

It is important to note the limitations of the reflections of the participants interviewed for this paper. Only a small proportion of the total number of participants were interviewed ${ }^{54}$, and while they were chosen in order to represent diverse points of view, there will be other perspectives not captured in this paper. Nevertheless, the interviews do give a sense of how the procedural decisions of the Court impacted the expert conferences.

\section{A. Did the expert conferences and joint reports help the proceeding?}

The most important question is whether the expert conferences and the joint reports actually helped the judge and the parties in the proceeding. Did they help the participants better prepare for mediation and the concurrent evidence sessions? Reflecting on this afterwards, Justice Forrest

\footnotetext{
54 Two barristers, two solicitors and two experts, from both the plaintiff and defendant sides, were interviewed for the research project. For more information see the explanation of the methodology set out in the third section of the Appendix.
} 
and Associate Justice Zammit both said expert participation in expert conferences and the preparation of the joint reports greatly assisted the Court. Justice Forrest said that the conferences "clearly reduced the number of issues before the court" due to the agreement of the experts and the joint reports. ${ }^{55}$ Associate Justice Zammit also affirmed the value of experts producing joint reports:

[...] issues were narrowed in the joint reports [and] by the end of the conclaves and the production of the joint reports the parties had in effect agreed on a very significant amount of information, so that the Court was able to dispose of that in the running of it because ultimately, things they agreed upon, there was no point traversing it unless it was for the benefit of educating the Court. ${ }^{56}$

Similarly, most of the legal practitioners said that the participation in expert conferences and the production of joint reports was useful as it focussed the parties' attention on the key liability issues. From their remarks it is possible to identify three key benefits to the procedure: first, it narrowed the issues in dispute; second, it encouraged greater accuracy and honesty from the experts; and third, it assisted in their preparation for trial. The specific comments of the participants are revealing. One solicitor said that they were "extremely helpful" as they "crystallised the debate". ${ }^{57} \mathrm{He}$ explained that the second joint report from the largest expert conference "contained a succinct identification of where there was agreement and non-agreement" between the experts, summarising 2000 pages of expert reports into 40 or 50 pages. ${ }^{58}$ Similarly, one barrister said the joint reports were a "huge time saver" and "hugely advantageous" because by the time the experts were giving evidence in court "all that was left to argue about were the things that they had confirmed were the issues between them."59 Speaking more generally, he said that he thought the default position is that joint reports "will always be useful" and that while in some cases the cost of getting the experts together might outweigh the benefit, this would be "the exception rather than the rule." 60

The other barrister said that expert conferences and joint reports were "essential" because when experts met without the lawyers "there's likely to be a greater honesty, less posturing because they are speaking with their own peers, and so if one of them says something silly or is clearly an

\footnotetext{
55 Interview with Justice J Forrest (8 August 2014, Supreme Court of Victoria, Melbourne).

${ }^{56}$ Interview with Associate Justice Zammit (13 August 2014, Supreme Court of Victoria, Melbourne).

57 Interview with solicitor involved in proceeding (20 February 2015, Melbourne) ('Interview with solicitor $\left.\mathrm{A}^{\prime}\right)$.

58 Ibid.

${ }^{59}$ Interview with barrister involved in proceeding (Morning of 24 February 2015, Melbourne) ('Interview with barrister $\mathrm{A}^{\prime}$ ).

${ }^{60}$ Ibid.
} 
advocate, the other one can easily undermine it." 61 He said that he thought the process it "injects great discipline" and "can only be productive of a narrowing of the issues." 62 It allows them to more properly deal with the issues raised in the other experts' reports and to assist each other in understanding the evidence they are putting before the Court. ${ }^{63}$ He explained that this also helped the parties:

I think that everybody saw an advantage; those who thought they were stronger on the science saw an advantage, would see that in a conference their experts were likely to be more persuasive and persuade the others to the benefit of their views; and those that thought they were weaker on the science might have thought well, better that we know that now rather than later. It's all going to be exposed at some later stage, so let's crystallise it and see what the issues are. ${ }^{64}$

It reduced the debate by encouraging consensus between the experts. This was very helpful to trial counsel because it provided a foundation for the concurrent evidence sessions and could be used in preparation for cross-examination. ${ }^{65} \mathrm{He}$ said that:

[...] instead of having two thousand pages of expert reports from everybody on different topics, I could take the joint report and realise there's quite a bit more consensus on this then you would realise if you just picked up the separate expert reports. So I thought that was very useful, and it crystallised my focus [for] cross examination. ${ }^{66}$

The other barrister similarly said the joint reports "enabled the judge and the parties to document an agenda for the concurrent evidence sessions" and for the parties to "prepare the cross examination by reference to the sequence of topics that were expected to be canvassed." 67

However, one barrister did express significant reservations and concerns about how the experts were divided up in the expert conferences, a decision that also had consequences in the concurrent evidence session. He said that the division of the experts into more specific areas of expertise had some problematic consequences. He said that the "separation" and "artificial distinctions" had the effect of "people in one silo who had expertise were not able exercise any kind of check on another

\footnotetext{
${ }^{61}$ Interview with barrister involved in proceeding (Afternoon of 24 February 2015, Melbourne) ('Interview with barrister $\left.\mathrm{B}^{\prime}\right)$.

62 Ibid.

63 Ibid.

${ }^{64}$ Ibid.

65 Ibid.

66 Ibid.

${ }^{67}$ Interview with barrister A, above n 59.
} 
silo that didn't have that expertise but was starting to go into that area." ${ }^{68} \mathrm{He}$ thought that this was one of the main reasons why the need for more testing arose in the conferences, and was of the view that if there had been more experts in the conference together sharing their expertise, some of the testing would have been avoided. ${ }^{9}$ He said he did not know what the solution to this problem would be, but that it was important for the Court to bear in mind. ${ }^{70}$ His critique indicates how difficult it can be for the legal process to divide up areas of expertise into different groups for expert conferences, and suggests there will be artificiality in any decision. After all, the experts are all going to be dealing with the same factual situation so there are likely to be areas of overlap.

As the expert conferences are meant to help the Court better understand the areas of agreement and disagreement between the experts, the perspective of the experts is particularly important. Both experts interviewed found the expert conference process and the production of joint reports valuable. One said it improved the accuracy the expert evidence, and clarified the issues for consideration by the experts. He said that:

[...] points were debated, rechecked, and corrections made to drafts of conclave reports where necessary. Our reports often went through half a dozen drafts before we submitted them. We did not always agree at the end. ${ }^{71}$

He said that the joint reports ended up being a fair representation of the opinion of the experts:

I think the conclave reports were reasonable summaries, although pretty long-winded, of the various interpretations of the physical facts of the events leading to the conductor failure and fire. To a reasonable extent the ideas came together, and some initial views were modified as the result of these exchanges. But after all some differences of opinion remained. If individual presentations had been made to the court it would have been even less efficient than what actually transpired. ${ }^{72}$

The other expert interviewed expressed similar views. He said the conference and joint reports were "very useful" and that they "provided insight into how the data or analysis of others was being used and interpreted." 73 It allowed the experts to "work as a team to extract the good bits of all our work." 74 He said that the experts worked together to conduct a "technical review of all of the available data" and that this allowed them to "assess and appropriately award certainty or

\footnotetext{
68 Ibid.

${ }^{69} \mathrm{Ibid}$.

${ }^{70} \mathrm{Ibid}$.

${ }^{71}$ Interview with expert (23 February 2015, by email) ('Interview with expert A').

72 Ibid.

${ }^{73}$ Interview with expert (24 March 2015, by email) ('Interview with expert B').

${ }^{74}$ Ibid.
} 
uncertainty based on the inputs." 75 He said that the process "did a great job of providing widespread dismissal of really bad science."76 They also "allowed the court to focus on the areas of disagreement" and that the experts made "very significant headway on most areas of technical interest." 77 The process allowed the experts to "[dig] deep into the nuances of terms and the minutia of some of the methodologies [...] and present a cohesive story that would have been difficult territory and very fine detail for the general court proceedings." 78 He said that the expert conferences shaped his reports and analysis and gave him an opportunity to "enter into dialogue and understand how my analysis was feeding into or contradictory to the work of others." $79 \mathrm{He}$ said that if they had a couple more days to consolidate their views, they could have avoided "roughly a week of cross-examination." 80

Despite these positive remarks, he did have some criticisms. He said:

It is also naïve to think the conclave was not adversarial; it was. We were trying hard not to form teams, but the three parties who had employed experts were not mixed physically or in argument, and generally the [experts] abstained rather than contradict[ing] weak argument put forward by someone working for the same parent client. ${ }^{81}$

He said that problems were caused by experts having "little to no overlap on the specific fields of discussion". This remark is particularly interesting given the criticism that the conferences should have been less specific and more general. In addition, the professional reputations of the experts were such that "there was such a high cost to backing down that the opportunity for concept development was very limited." 82

The interviews conducted suggest that the expert conferences and joint reports fulfilled the purpose of Justice Forrest's rulings. They narrowed the issues in dispute by showing where experts agreed and disagreed. The interviews with the experts indicates that this was because it allowed the experts to have a technical discussion about their evidence, permitting a discussion about methodology and starting assumptions. This suggests splitting up of experts into smaller groups was an appropriate strategy; if the conferences had been larger including people from

\footnotetext{
${ }^{75}$ Ibid.

76 Ibid.

77 Ibid.

78 Ibid.

${ }^{79} \mathrm{Ibid}$.

${ }^{80}$ Ibid.

81 Ibid.

82 Ibid.
} 
different areas of expertise, this would have caused greater difficulty. Nevertheless, the criticism of the barrister about the risk of over-fragmentation ought to be borne in mind when deciding how to group the experts.

\section{B. Involvement of a Judicial Officer as a moderator}

Justice Forrest tasked Associate Justice Zammit with managing the administration of the expert conferences, and she sat in the larger expert conferences as a moderator. The participants' experience suggests that having an independent person in expert conferences is beneficial, particularly when there are more than three or four experts. Associate Justice Zammit was able to help the experts with managing the dynamics of the discussions, as well as deal with difficult personal situations that arose. The perspective of the experts is particularly instructive: one thought that the conference he participated in would have been compromised without her involvement.

Justice Forrest and Associate Justice Zammit both said having a judicial officer as a mediator was useful. Justice Forrest said the process had demonstrated to him "the need to have an impartial person assisting the experts." 83 He explained that:

It was far better that Associate Justice Zammit was either in the room with the experts or alternatively directly accessible to the experts if they needed assistance. Having someone with the stamp of judicial authority, I perceive has assisted greatly in the management of the conferences and I would recommend that course if resources permit to any case or significant case requiring expert conferencing. ${ }^{84}$

He said the appointment of Associate Justice Zammit as a moderator of the larger expert conferences was very helpful:

There is no doubt, having spoken to the experts in court, that her role was vital. She became a liaison point with my staff and myself. But she also gave them quite clear advice and assistance in relation to how the case would proceed, how they would give their evidence and as to how to manage. [...] It was clear that appointing an Associate Justice to assist was a very wise move because she was able to exercise some judicial authority over the experts and at times was also open to deal with matters on a [judicial] basis. So, her impact was significant. ${ }^{85}$

\footnotetext{
${ }^{83}$ Interview with Justice J Forrest, above n 55.

84 Ibid.

85 Ibid.
} 
Associate Justice Zammit said her involvement, particularly in the larger conferences, offered significant advantages. She reported she was able to help resolve many uncertainties the experts had about their role, and regularly had to reassure them that they were going about the process in a sensible way that was going to be of assistance to the Court. Her involvement meant the Court could have confidence that the large conferences were kept on track, and ensure that if they proposed further scientific investigation, this was considered carefully by the experts, and that it was necessary rather than only desirable. ${ }^{86}$

It also allowed her to avoid delay by exercising her judicial power to quickly deal with situations as they arose. The consequences of any delay was significant due to the size of the proceeding. She explained:

Well I think what it enabled me to do was it was a one-stop shop. If we had an independent moderator who was a senior member of the bar or a senior solicitor, they would have been limited in what they could do or decisions they could make. I think the real advantage [of] what we did is took it out of the hands of the lawyers and put it straight into the hands of the court, and said the court is now managing this part of the process, because the court knows what it wants. ${ }^{87}$

This allowed her to make, where required, orders for further testing, and to do so understanding how such an order would affect the overall timeline of the trial. For example, at one stage a close relative of one of the expert witnesses died and an exercise of judicial power was needed to ensure that the parties could make submissions on whether the conference could continue, and a decision be made as quickly as possible. 88

A related benefit to having a judicial officer as moderator was that it helped the experts feel comfortable with the process. Associate Justice Zammit said that a recurring concern of the experts was that if they veered from their given opinions during the conferences, they would face repercussions from their own lawyers and it could make them a target for cross-examination (particularly as some of them had "been victims of fairly horrific experiences in court"). Her Honour explained:

While clearly they have got to give their evidence and parties must be able to test the strength of an expert's evidence and opinion, I was able to reassure them that in the context of concurrent evidence the Judge leads the way, so the first person to talk to them and ask questions of them is the Judge

\footnotetext{
${ }^{86}$ Interview with Associate Justice Zammit, above n 56.

87 Ibid.

88 Ibid.
} 
and the Judge would be directing and guiding that very carefully, and then would invite crossexamination on certain topics [...]. 89

Associate Justice Zammit said that different management styles were required depending on the size of the conference, the complexity of the issues and the background of the experts. ${ }^{90}$ While she did say that the personalities of the experts did have an impact on how the conferences proceeded (an issue addressed below), the main difficulty was "the experts' sense of conflict between their obligation to their client and the Court". ${ }^{91}$ She said that many of the experts were concerned about how their instructing solicitors and barristers would react to the joint report:

While it may have never been specifically articulated, the fact that I spent an inordinate amount of time having to reassure them that the production of a joint report was ordered by the Court and their lawyers understood that they would produce the joint report together and that they would not come under any criticism. [They were] quite concerned saying things in one conclave and making concessions if it was going to be detrimental to their instructing party. Their role as a party's expert and their role to help the court did not always sit comfortably with them and you can understand why. ${ }^{92}$

These concerns were somewhat offset by her involvement in the conferences. The experts could be reassured by someone with both the authority and knowledge to provide that reassurance. It is easy to imagine that in other conferences where there is no moderator or input from a judicial officer, experts could feel very isolated and unsure of their obligations and the court process.

The lawyers were broadly supportive of the role of the Associate Judge in moderating the larger expert conferences. One barrister explained that:

I thought that was essential [...] [as it] focussed the issues, organised the timing of the process because we had multiple experts, so there were mechanical issues like that. She assured that there was no misbehaviour from the experts. Her presence was a disciplining approach, and she could assist in working out the mechanics of the joint report production. I thought that was extremely useful, particularly [...] [as] one of our conclaves [...] had about 8 experts or something like that, and you need somebody to corral that, otherwise one person who's got a strong personality takes over and in part diminishes the process $[\ldots]^{93}$

\footnotetext{
${ }^{89}$ Ibid.

${ }^{90}$ Ibid.

${ }^{91}$ Ibid.

92 Ibid.

${ }^{93}$ Interview with barrister B, above $\mathrm{n} 61$.
} 
He also said that the involvement of an associate judge can help the experts in producing joint reports that are "crystallised to the form that is more suitable for the end product, which is lawyers using it" and that he thought that "Associate Justice Zammit's conduct in these conclaves was nothing short of excellent in that regard." 94 He said that it should be a standard procedure in class actions where there are three or more experts in the expert conference. ${ }^{95}$

It is important to properly describe and define what is an appropriate role for a judicial officer in an expert conference. One solicitor objected to describing the role of the Associate Justice in the expert conference as a 'mediator'. He said that the role more properly thought of as a facilitator who assists with "the preparation of a joint report that enables each expert to express their opinion having heard and considered the views of the other participants." 96 To this end, the joint report should identify "the issues remaining in dispute in a manner consistent with the discussion in conference, and [...] adequately [detail] the extent, basis and impact of the differing opinions." 97

Connected to this was his concern about the influence of the Associate Judge distorting the outcome of the conferences. He said that the influence of the Associate Judge in the expert conferences meant there was a risk of the experts would feel pressured into making compromises and reaching agreement. He said that "care needs to be taken to ensure the desirability of reaching agreement is not overstated." 98 He said that some of the expert witnesses retained by his party "were clearly under the impression as a result of the Associate Judge's comments that it was their responsibility to endeavour to agree with [the other experts] and that disagreement was discouraged." 99 He said that this had led to situations where experts "agreed with matters relating to new testing where they had not been provided with the underlying data" and did not have sufficient time to consider the proposal. He further said:

It also led, on occasions, to experts agreeing with propositions on the basis that they agreed with most of what was said, and didn't feel that qualifying their agreement was consistent with the spirit of co-operation they had been asked to embrace. ${ }^{100}$

The risk of the 'spirit of cooperation' pressuring experts into compromising their positions is, at least to some degree, probably inescapable in an expert conference. However, experts should be

\footnotetext{
94 Ibid.

95 Ibid.

${ }^{96}$ Interview with solicitor involved in proceeding (9 June 2015, by letter) ('Interview with solicitor B').

${ }^{97}$ Ibid.

98 Ibid.

${ }^{99}$ Ibid.

100 Ibid.
} 
reminded that it is most important they give their full view of the evidence, even if it means disagreeing with the other experts.

Most importantly, the experts found the involvement of the Associate Justice very helpful. One expert was surprised, saying that he "expected the Associate Justice to be a grumpy crotchety old bloke with no interest in the process of the discussion or science, and who would quickly control the discussion to keep it progressing." In contrast to his expectations, he said that:

Within the conclave Associate Justice Zammit was a kind and caring influence to keep things moving and gave us clues into legal language. In this way the guidance was great, and the open scope for the work allowed us to navigate and document the disagreements and agreements very well. ${ }^{101}$

He said that having the Associate Judge as moderator was "essential" as she "kept all parties honest", "reduced bullying and assisted in the flow of the discussion". He complimented Associate Justice Zammit's "stern yet compassionate" moderation of the conference. He said when the Associate Judge left the room "there was a clear power vacuum and the discussion generally stalled." He said that "at times various experts engaged in destructive or bullish behaviour", but this was quickly corrected by the general assembly and reinforced by the Associate Justice as "unhelpful". ${ }^{102}$

Despite the involvement of Associate Justice Zammit, this expert identified "two significant vulnerabilities inherent in the conference process as 1) time wasting and 2) the inequitable power residing in the group report editor." 103 He said "time wasting was difficult to control as the inclusive and open nature of the conclave required all parties to have a voice even if that voice lacked clear focus or supporting data, and the Associate Justice was not across the technical content enough to identify and curtail the strategy." 104 The possibility of inequitable editorial power was addressed by "continual review of the position by the assembly and careful observation of the Associate Justice." 105

The other expert was also of the view that having an associate justice as moderator was useful in the larger conference:

\footnotetext{
101 Interview with expert B above $\mathrm{n} 73$.

102 Ibid.

103 Ibid.

104 Ibid.

105 Ibid.
} 
The associate justice was very helpful in guiding us through the procedures, keeping us somewhat to schedule - not an easy task with several strong minded, and verbose, individuals on the panel.

[...] The technical discussions proceeded somewhat independently of the associate justice. ${ }^{106}$

This is common sense: trying to manage a discussion of nine people with different views without any moderation is very difficult. This difficulty is increased when the material being discussed is highly complex and is the discussion is taking place in the context of high-pressure litigation. The person moderating the conference may not have to be a judicial officer, although the comments of Associate Justice Zammit suggest that this may be helpful in some situations. The most important thing is for there to be a person who has the skills necessary to help ensure the conversation is productive, that the opinions of the experts are respected and they are not pushed into a false compromise, and that the report produced is in a form that is useable by the legal practitioners and ultimately the Court.

\section{Administration of the conferences}

Many of the problems caused by the scale of the expert conferences were not strictly legal in nature. This included identifying what documents each expert had accessed in writing their reports, or helping the experts understand their role within the expert conference. The solicitors raised concerns about the lack of oversight the parties had over the amount of money spent on extra testing during the conferences, suggesting the parties should have been able to make submissions to the court about whether it was necessary. Associate Justice Zammit said there are a number of lessons to draw from the administration of the expert conferences in the Kilmore East bushfire proceedings. Some are basic: for example, she quickly found that there was "no point getting an independent scribe" as "when you were dealing with such technical matters [...] dictat[ing] it would have been so difficult", so instead it was necessary to rotate the scribe role amongst the experts. ${ }^{107}$ The ease or difficultly of managing the conferences was somewhat dependent on the size of the conference. Her Honour said that in contrast to the larger expert conferences, the smaller ones "ran almost independently" and required very little outside input apart from some brief instructions and an agenda to guide discussions. 108

Associate Justice Zammit said that an "inordinate amount of time" was spent at the beginning of each conclave making sure the experts had access to and had read all the necessary information,

\footnotetext{
106 Interview with expert A, above $\mathrm{n} 71$.

107 Interview with Associate Justice Zammit, above n 56.

108 Ibid.
} 
including all of the expert reports, the scholarly articles that had been relied upon, and the letters of instruction. ${ }^{109}$ Her Honour recommended that in the future there should be a defined process for ensuring that these documents are provided to the experts well before a conference takes place. She noted there were some significant dangers in failing to ensure that all experts had the same set of documents:

[The] danger was that they were handing each other documents in the conclaves. I was concerned about what they were giving each other, and whether the documents had been discovered, [I had real] concerns about this informal process may be waiving documents that have been given in confidence, all of a sudden to one another. ${ }^{110}$

In addition, she said more information prior to the conference about the background of the experts and a summary of contents of their reports would have assisted in managing the conferences:

[...] the difficulty is that the reports were of such a complex nature that really sitting there and reading them on my own was of limited benefit, so I think a summary of what each of their reports addressed would have been extremely useful, and again one which the lawyers might prepare with the assistance of the expert. [...] Perhaps documentation which specifically, and again if you are doing this front end and saying here are the issues, here are the questions we need to ask, you can then say well expert $X$ has provided this opinion which addresses this particular issue. Expert $Y$ on the other hand says this. From my point of view if I had that at the beginning that would certainly have been of assistance. More importantly it would have been of great assistance to the experts. ${ }^{111}$

Her Honour said the court should at an early stage in the proceeding provide all the experts with an explanation of the role of experts, how their reports would be used during the expert conferences, and how it would be pulled into a joint report and submitted to the Court. Experts often struggled with the concept of the joint report, with some thinking that they had to come to agreement on everything. She thought that some of this misunderstanding might be mitigated with better instructions. ${ }^{112}$ She said:

I think that if they understood that process at the beginning they may in fact draft their individual reports a bit differently. Because [...] I think experts draft a report as we all do, thinking your audience is the lawyer that has instructed you. It might make it into a courtroom, but it might not. But, if from day one you are writing that report knowing that it is on the basis that before it gets to

${ }^{109}$ Ibid.

110 Ibid.

111 Ibid.

112 Ibid. 
the courtroom it is going to also be analysed and discussed with your peers in an informal setting and that collectively a joint report is to be prepared [it may influence the way that report is written].113

To this end, Her Honour said that it would have been helpful to provide the experts with a sample joint report from another case with confidential information redacted. ${ }^{114}$ The issue could also be addressed by holding a meeting with all the proposed experts prior to the commencement of the expert conferences. Her Honour explained:

[...] it would be useful to actually meet with the experts [before the conclaves], maybe even inviting them into Court [...] to assess what information they received, [...] what instructions they had received at that stage so that $\mathrm{I}$ [could be] sure that all the experts are fully equipped with all the information they need and that we are comparing apples with apples. ${ }^{115}$

Such a meeting would have a number of other benefits, including enabling the Court to provide the experts with a list of issues that needed to be addressed. It could also provide an opportunity for the experts to have some input into the agenda for the conferences, and the questions in that agenda. As Associate Justice Zammit pointed out, they are "better equipped to formulate those questions" than the Court or the parties. Further, it would give the Court staff an opportunity to discuss with the experts the equipment they would need for the conference, whether that be computers, projectors, whiteboards or any other necessary material aids. ${ }^{116}$

The lawyers were generally satisfied that the process had worked well. The running of the conferences was left in the control of the Court. One solicitor said that the only guidance he could recall giving to the experts was that "if [they were] not writing the joint report [...] [they] should check it extremely carefully" and to make sure that "they weren't rushed, and if they were signing a joint report make sure it precisely reflected their view".117 The other solicitor said that they "provided guidance to [...] experts on what the conference process was likely to involve" but that "the quarantining process prevented any ability to manage the expert expectations during the conference."118

\footnotetext{
113 Ibid.

114 Ibid.

115 Ibid.

116 Ibid.

117 Interview with solicitor A, above n 57 .

118 Interview with solicitor B, above $\mathrm{n} 96$.
} 
One solicitor made some general observations about the process. He said that the questions considered by the conference should be "very specific" as "high level questions were of limited utility in attempting to identify the issues ultimately in dispute between the experts." 119 The lack of specificity in one conclave resulted in the evidence of two experts "passing like ships in the night" as one expert had not addressed the issues with sufficient specificity. He also said that smaller conferences with narrow issues were preferable to large ones, ${ }^{120}$ presumably for a similar reason. He said it was important that expert conferences were scheduled "sufficiently far enough in advance of trial, or the trial timetable adjusted, to allow further [conferences]" where expert witnesses "seek to set out in the joint report significant material in support of their position, where those issues had not been properly considered" in the expert conference. ${ }^{121}$

The legal practitioners expressed concern about some aspects of the expert conference process. The first was the amount of money that was spent during the further testing required by some of the expert conferences, with one solicitor raising the "disconnect between the further work [of the experts] required and who was paying for it." $122 \mathrm{He}$ said:

[W] [saw] on a couple of occasions coming out [of expert conferences] that there were three or four months further work being authorised, and frankly there's a point of diminishing return. [...] [T]he experts would always caveat "well, I could do this to firm up this point" and the court would say yes, you should do that, it would help us with the trial, and at times the cost was pretty substantial [...]. Now, in our case, it turns out that was tolerable, but in a lot of cases you'd have the client saying "well, I actually didn't budget for any of this." [C]lients all the time say to us, "we know you as lawyers want to have that, but we're not spending the money, we're not satisfied on a costbenefit analysis that that's a useful exercise" and we'd say we'd really like to run the case, and they say "no, we're not authorising you to do it."

It is something to be aware of [...] [in this case] my sense was there was no discussion of what's the cost, who's paying it, what's the likely benefit before [going ahead with the further work]. ${ }^{123}$

The other solicitor echoed these concerns, saying that one conference in particular had been a "rolling maul of further reports and testing" due to the "notion that the entire process would be

\footnotetext{
119 Ibid.

${ }^{120}$ Ibid.

121 Ibid.

122 Interview with solicitor A, above n 57 .

${ }^{123}$ Ibid.
} 
'expert-driven' rather than 'lawyer-driven.'"124 He made two points about an 'expert-driven' process:

a) First, as a matter of principle it is imperative that the parties through their lawyers have a chance to address the court on the utility and fairness of further reports and testing. This did not occur.

b) Secondly, it emerged from [...] documents that far from being 'expert driven' many of the further reports and testing were at the request or instigation of the [another party's] lawyers. ${ }^{125}$

It was his firm view that assessing whether further reports or testing was required

[...] should not be made by experts alone, and not in the absence of the parties and their legal representatives properly informing themselves as to the appropriateness of the proposed course of action and being afforded an opportunity to address the Court on the issue. ${ }^{126}$

The second issue, raised by one of the barristers, was that the restriction placed on the experts preventing them from introducing new material during the expert conference stood in the way of providing the best information to the Court. He said that in cases where the scientific evidence is evolving over the course of the proceedings, more leeway should be given to the experts. ${ }^{127}$ Noting that the Court did "a wonderful, wonderful job with this litigation" he said that:

There was a couple of instances where it was clear that very important lines of discussion were sought to be raised in the conclaves, and were shut down because the moderator, or someone else, saying "that's not covered in a report that was written a year ago, therefore we're not touching it." Well hang on a second: that was a year ago, and we've had a twelve month trial in the interim, and there's a lot of stuff that's come out. The control over the content of the concurrent sessions was too dogmatic and given the importance of this litigation [...] and the fact that there had been at different times questions as to whether a party was entitled or allowed to file a reply or a supplementary report for an expert or not, we got [...] inconsistent messages about what we were expected or allowed to do. ${ }^{128}$

\footnotetext{
${ }^{124}$ Interview with solicitor B, above $\mathrm{n} 96$.

125 Ibid.

126 Ibid.

127 Interview with barrister A, above n 59.

128 Ibid.
} 
He said that there had been occasions where an expert was refused permission to provide a supplementary report on a particular issue, or raise it in the expert conference, only for the issue to be recognised at trial as actually being critical to the determination of the case. ${ }^{129} \mathrm{He}$ said that:

That was infuriating [...] and there should be clearer procedures and expectations firstly as to when reply reports are to be prepared. And this can be done efficiently - there's any number of ways it can be done - reply reports can be prepared, and the conclaves can include a recognised ability for an expert to raise a matter that the expert considers relevant. ${ }^{130}$

The other barrister did not share this view. He said "there was nothing to stop that expert when the quarantining order was lifted [from] going back to his or her party and saying 'look, there is this other issue that I've thought about'" and then this information being the subject of a supplementary report and dealt with under the procedures for the late filing of evidence. ${ }^{131} \mathrm{He}$ said that it must be remembered that expert evidence had to strike a balance between finding the 'truth' and the practical restrictions of litigation. He said that even though there is "always a further investigation, always a further test, perhaps even a further theory to come up with" there has to be a point where the experts stop their investigation. ${ }^{132}$

There are always going to be aspects of the way that a court manages a case that leaves the parties unsatisfied. Nonetheless, the concerns raised by the lawyers are important to note. It seems the starting position should be that if extra resources are going to be devoted to additional testing, the Court should give the parties the opportunity to make submissions on whether it is necessary.

The two experts interviewed were generally happy with the conference process, with some reservations. As neither expert had previously participated in expert conferences, they did not really know what the process would entail. One said that he:

[...] expected an Ego-fest with balding grey haired men each backing themselves and being unprepared to learn or listen. This was partially true of [some experts who did not] significantly add to any insight on the topic, but was quite wrong of [a number of] the conclave meetings. ${ }^{133}$

He said that he received almost no information about how the conference was to proceed, and what he would be required to do during the process:

\footnotetext{
129 Ibid.

130 Ibid.

131 Interview with barrister B, above n 61 .

132 Ibid.

133 Interview with expert B above $\mathrm{n} 73$.
} 
I had very little to no guidance on how to interact, or what was expected from the conclave. The legal team indicated they could offer no guidance, and there was no guidance or counsel within my parent company. I read through the contract carefully and used this as the rules for engagement. ${ }^{134}$

He said that most of the experts conducted themselves appropriately, explaining "we had a number of good and experienced folk in the conclave that allowed the flow of discussion to continue and showed leadership in concessions and thinking." 135 They decided on process for working through the evidence. He explained:

We developed an editorial process where people could recommend the improvement of any paragraph they agreed with. These basic rules (and a few to follow) would have been helpful as "guidance notes" i.e. non-prescriptive methods for facilitating conclave success. ${ }^{136}$

He said that this process changed throughout the conference. For example, in response to one expert providing a page of text into the draft only 12 hours before submission, the experts imposed limits on when new material could be included into the draft.137

One expert explained that material and opinions were shared during the conferences in conversations, through the written editing of the documents, as well as the provision of supporting documents and emailed commentaries. ${ }^{138}$ The expert explained that while teleconferencing was "not as effective as face to face meetings" it was "still a reasonable and necessary compromise for a foreign expert." He said that:

With some creativity even a demonstration of the physical behaviour of a model could be communicated this way. The [significant] time difference was hard to manage. [...] There is a half second or so time lag in the communication over the internet which impedes the natural flow of questions and answers. ${ }^{139}$

The other expert said that having the experts meet after the experiments underlying the expert evidence were either well developed or concluded was "not ideal as the experiments at times did not address the requirements of the analysis." 140 He said in order to be "truly collegiate" in their work, the experts should have met "early and often" to "discuss ways the data could be viewed

\footnotetext{
134 Ibid.

135 Ibid.

${ }^{136}$ Ibid.

137 Ibid.

${ }^{138}$ Interview with expert A, above $\mathrm{n} 71$.

139 Ibid.

${ }^{140}$ Interview with expert B above $\mathrm{n} 73$.
} 
and analysed." 141 He said that this could also have been accomplished through emails and the sharing of working documents. ${ }^{142} \mathrm{He}$ did say that this had occurred to some extent "through the iterative publication of reports, where the reports could draw on the previous work, and the work of others to view or review a particular topic." 143 The expert acknowledged that a longer and more collaborative investigation process would run the risk of allowing parties to game the system. Nevertheless, he was still of the view that "meeting early and often, ideally before anyone publishes anything", and allowing discussions about the broad aims of the research, would lead to "less diverging methodologies, or at least experiments and publication that aimed at addressing common perceived hypotheses." 144

The comments of the experts draw our attention to the tension between the needs of science and the needs of the trial. While it may be better from the perspective of the experts to meet earlier in the proceeding to plan how best to conduct experiments to try and answer the scientific questions of the case, this would not be feasible in many, if not most, trials. Moreover, a trial and a scientific inquiry have different aims: a trial seeks to allocate responsibility on the basis of probability; whereas scientific inquiry is aims for a more complete and certain understanding, and one that is not so constrained by the need to reach judgment. On a more mundane note, the expert's comments also indicate the Court should do more to help experts understand their role in the proceeding, and the role of the expert conferences.

\section{Impact of personalities and attitude of experts}

One of the major concerns raised about expert conferences is that the personalities of the experts could have an adverse impact on how accurately the joint report reflects the views of the participants. The experience of Associate Justice Zammit as moderator in the larger expert conferences suggests that this concern is warranted. She said she found herself actively managing the conference she was involved in to ensure everyone had an opportunity to contribute:

There were definitely stronger personalities, and sometimes even if it was not personalities there were people who were regarded as being leaders in their field of work, and so people automatically gravitated to their view. We had one gentleman who was $[\ldots]$ eminently qualified and he was quite assertive in his control, compared to one other fellow who was just a very timid individual and I

\footnotetext{
${ }^{141}$ Ibid.

142 Ibid.

143 Ibid.

144 Ibid.
} 
think felt quite intimidated and overwhelmed. [...] You had to really allow him the opportunity [to contribute]. ${ }^{145}$

Her Honour said she was careful to ensure that the experts who were quieter had an opportunity to be heard during the conference, and that each expert could be confident that their view was going to be recorded. She thought this was a particular concern with larger conclaves:

There would be a real danger in conclaves where there is more than two or three $[\ldots]$ that voices would get lost and less confident people may not in fact be represented as well. ${ }^{146}$

Associate Justice Zammit said that the attitude of the experts was critical to the success of the conferences and that she was impressed with the seriousness with which they approached their role. Further, the conferences helped the experts move from an adversarial approach to a more scientific one:

The more time they spent together [...] the easier they found it to move into that [the scientific] role as opposed to an adversarial role, and [...] they were able to be critical of one another and their work, but in a more scientific rigorous way as opposed to an adversarial way, [...] you saw them transform back into that and want to share their scientific experience to solve the problem. It suddenly became the big problem solving exercise $[\ldots]^{147}$

This had real benefits as it allowed the experts to control their problem solving, and they had the autonomy to be proactive in identifying information they needed to resolve differences in their evidence. The experts themselves worked out some management issues, with the natural leaders taking control of the conferences to ensure they were effective. In one of the larger conferences one expert took it upon himself to prepare defined questions and issues for the other experts to start discussion. Associate Justice Zammit said this was very helpful as she would not have had the scientific knowledge to prepare that kind of document. ${ }^{148}$

The lawyers were not overly concerned about the risk that the personalities of the experts would have a detrimental impact on the conferences. One barrister said that personality was a factor practitioners always had to take into account when retaining expert witnesses as it is important to have an expert who will stand up in the witness box for the view they have properly formed. ${ }^{149}$

\footnotetext{
${ }^{145}$ Interview with Associate Justice Zammit, above n 56.

146 Ibid.

147 Ibid.

148 Ibid.

149 Interview with barrister A, above n 59 .
} 
He said the same was likely to be true in expert conferences: an expert who is too timid or too bombastic will probably not be selected to provide evidence. ${ }^{150}$ He said that during the conferences, as long as the moderator is "sufficiently across the competing reports" they will be able to see when an expert is "either being bombastic or possibly evading the real questions" or if an expert "is perhaps timid by personality and maybe agreeing to things that don't reflect the expert's actual agreement." 151 He said that:

The moderator is not there to shore up the expert, but they can ensure that the level of debate does not involve bullying. And, that the experts' joint report reflects the genuine views of the experts. Now, there is only limited scope for the moderator to do that, because as I say, the experts kind of need to stand up for themselves. 152

He said this did not mean there should be a moderator in all expert conferences. In smaller conferences with only two or three experts, he said that the risk of personality affecting the outcome was just a risk the court and parties had to manage. He explained:

Everyone has got to be alert to the possibility, and you know, if an expert has been telling you something for months and then they go into a conclave, and out comes this joint report that's taking a different line, you're going to be sitting down with your expert and [asking them to explain themselves]. [...] And if the expert answers "well, I didn't mean [to agree to that]", well then you've got a conclave that has gone awry, and then you've got a problem that you'll just have to deal with openly with the Court. [...] [T] he expert is rightly going to be criticised by the judge for signing the report in those circumstances. Now hopefully that sort of thing isn't going to happen very often as the lawyers should have chosen the expert who can defend him or herself and prepare the expert for the experience. ${ }^{153}$

He said that the risk was not going to be much more significant than during cross examination, and that as such, there was not a need to be "too overly protective".

I don't think that risk requires any higher level of precautions than what I've already described: the parties need to be alert to the risk, if there's a moderator they need to be alert to the risk, and when the joint report comes out, everybody is going to be careful to have a good look and see how it responds to what they've been getting told by their expert on their way through. ${ }^{154}$

\footnotetext{
150 Ibid.

151 Ibid.

152 Ibid.

153 Ibid.

154 Ibid.
} 
The experts had two quite different perspectives. One expert did not find that the personality of the experts had a detrimental impact on the expert conferences. He said:

Each person was treated with respect, and the tone of the conclave meetings was quite positive. While some members were quite outspoken, in my opinion everyone had the opportunities to present their interpretation of the facts, their simulations and their theories. ${ }^{155}$

In contrast, the other expert made extensive remarks on the impact of the personality of the other experts on the conferences. He said that the experts were quite partisan, and that "without really intending to we fell into teams by default [and] sat opposite each other in the room". 156 This was indicated by his own reflections on the conferences: he praised another expert for "effectively [carrying] the flag for the claimant" as he was the most technically proficient "in that team" ${ }^{157} \mathrm{He}$ also said that this expert "showed us how to concede by not defending weak argument."158 $\mathrm{He}$ said that the experts understood that there was a "sense of giving ground and [the experts] were all aware that other parties had paid well for advice that we were dismissing or reinterpreting" and that "some people would have some explaining to do at the release of the conclave reports."159

The impact of the personalities of the other experts did not surprise him, and he saw it as an inevitable part of working with other people. He explained that:

Each person used features of their personality to push a particular argument (again I think this is normal). From my perspective this generally was not a big problem, and we were able to moderate each other. I was glad that the most bombastic individual was aligned to my thinking, and appreciated the team strategy used in the discussions. The conclave environment is not for the meek and to play a role you had to be agile and attentive. ${ }^{160}$

Nevertheless, he did mention a number of issues that did cause some problems. He gave an account of the various strategies experts used to try and affect the outcome of the conferences. He thought one expert used "unclear communication" as a strategy to "infer possibility and complexity." 161 He said that time wasting was a significant problem, as "[w]ith the loose governance and inclusive intent of the conclaves cunning people with weak arguments could

\footnotetext{
155 Interview with expert A, above $\mathrm{n} 71$.

156 Interview with expert B above $n 73$.

157 Ibid.

158 Ibid.

159 Ibid.

160 Interview with expert B above $n 73$.

161 Ibid.
} 
waste a lot of time on things of no benefit." 162 He added that a real difficulty in the conferences was "stupid people". He explained that:

I don't mean this as a triviality, or to be particularly harsh, and it is not really coupled directly to the question of personality, but the people that couldn't keep up, or that were inflexible in their thinking consumed a lot of effort, and provided little to no insight into the science. ${ }^{163}$

He thought that if these people could be somehow excluded from the conferences, they would have worked much better. He said that some people "didn't get the concept of the group reports at all" and were unwilling to express clear agreement or disagreement with parts of the report, or would otherwise refuse to participate. 164

The expert's view of the impact of personalities in the conference is not surprising. Expert conferences do not escape the effect of normal group dynamics: there will still be people that do not get along, or have a personality clash with others. Some people will find it easier to contribute to group discussions than others. The view of the lawyers that it is just another thing to be managed is a sensible one. It does strongly suggest, however, that a moderator in larger conferences is important. The presence of an independent third party in the room who has the authority to manage the discussion is good insurance against the detrimental effects of personality.

\section{E. Quarantining of experts and relationship between the experts and the parties}

The final issue that was discussed in the interviews was the effect of the quarantining the experts, and the relationship between the experts and the party that retained them. There were different views amongst the lawyers about quarantining experts. One solicitor said that it actually "made it easier for us." He said that:

We are at such pains to try not to create an expectation or a desire for them to express some view, and we try to engage so neutrally with them, it actually made our life relatively easy with the court saying, well, tell me why you think this. We try to be as careful as possible with experts, you have to imagine kid gloves, because there is a tendency to read things into your communications. ${ }^{165}$

\footnotetext{
162 Ibid.

163 Ibid.

164 Ibid.

165 Interview with solicitor A, above n 57 .
} 
Both barristers said that the quarantining was "beneficial" to the process. One barrister said that the "non-involvement of legal representatives was absolutely crucial" as to do otherwise would contaminate the process. 166 He said that his view on this could be a result of the confidence he had in the experts his party had retained:

[...] I was pretty confident that I had some of the best experts that could ever be called in the area, so I suppose my happiness in not having legal representatives there was a function of the confidence I had in my own experts. Putting it another way, if you don't have confidence in your own experts, you're going to be less happy about being excluded as a lawyer, aren't you? So that was how I approached it, but I thought it was invaluable. You got honesty, you got rigour and you got a focus on the issue. ${ }^{167}$

The other barrister said quarantining was sensible as it allowed the experts to concentrate on their own opinions, and that the fact the Court protocol allowed them to speak to the experts afterwards about what had happened during the conclaves was sufficient. ${ }^{168}$ His only suggestion was that Court and the parties should explicitly recognise that the experts are "not trained (usually) to dissect language in the way that lawyers are." 169 Such a recognition requires "the joint report [...] be acknowledged to be an indication of the experts view on a particular issue" and probably a little loose in the language used. ${ }^{170}$ In the Kilmore East bushfire proceeding this led to some difficulty as:

The expert might have thought that they'd touched on a point, and then they were cross examined for an hour by someone [...] as to whether, you know, the location of the comma meant this, that or the next thing - you know, really finicky stuff. Excellent cross examination [...], don't get me wrong - but when the experts are doing their separate reports, the lawyers get to look at them, and say well hang on, what do you mean by that, that's not clear, you've got to do it more clearly, and so the written reports can be reliably a little bit more tight in their language. But, you're given a day in a conclave, a half day to write the joint report, a half day to finalise the joint report, it's going to be pretty loose in its language. ${ }^{171}$

He said this could be addressed by having a relevant scientist engaged not as an expert, but as a scribe to ensure the report was clearly written. He explained it did not justify the involvement of

\footnotetext{
166 Interview with barrister A, above $n 59$.

${ }^{167}$ Interview with barrister B, above $\mathrm{n} 61$.

168 Interview with barrister A, above n 59 .

169 Ibid.

170 Ibid.

${ }^{171}$ Interview with barrister A, above n 59 .
} 
lawyers because "you can imagine how it would end up. You'd never get agreement on anything, really. So it's better for the experts to do it, but everybody needs to recognise that it is rarely their forte to be super super precise in the language they use, particularly when it is contentious." 172

The other solicitor was more circumspect about the value of quarantining the experts. He said it exacerbated some of the issues with the expert conferences by limiting the parties' "ability to assess either the forensic utility to the determination of the common questions on the balance of probability or the cost benefit analysis in advance of the further reporting and testing." $173 \mathrm{He}$ was also concerned that new evidentiary material was introduced during the expert conferences. He said the introduction of "new material in this manner denied [my party] an opportunity to properly respond to the new material" and that it "inappropriately cloaked this new material and testing with the authority of having genuinely arisen out of the desire of the participating conclave experts to obtain it." 174

Quarantining the experts from the lawyers did create some difficulties for the experts as they could not ask questions of the people that had retained them. One explained that as it was his first experience of being an expert witness, he was not sure of the procedure and what documents he was permitted to refer to. He said that:

For instance, I did not know that there was a "court book" containing all documents until very late in the process. I am still not sure if I was allowed to access it. There was also a room of evidential items from the failed line. I never saw that either. ${ }^{175}$

He also noted how the role of the expert in the legal system is somewhat fraught, and it can be difficult to know what the role entails:

$[\mathrm{T}]$ here is an inherent conflict between the lawyers' adversarial role, representing the interests of their client, compared to the role of engineer, which is to ensure the safety of the public. ${ }^{176}$

The other expert said that quarantining was "essential" as it allowed him to focus on the conference. He explained that "[a]nswering enquires, and the possibility of influence by legal

\footnotetext{
172 Ibid.

173 Interview with solicitor B, above n 96.

174 Ibid.

175 Interview with expert A, above $n 71$.

176 Ibid.
} 
teams would not have been helpful." In addition, he said that "[t]he lack of lawyer presence also allowed a softening of consequence to the opinions facilitating concessions and agreement."177

\section{CONCLUDING REMARKS}

The participants in the Kilmore East bushfire proceeding agreed that the expert conferences and the production of joint reports was useful. For the judges and lawyers, having a summary of the voluminous expert evidence and a clear picture of where the experts agreed and disagreed was critical in their preparation for the trial. We can probably assume that it was also helpful for the final mediation. The experts managed to reduce the number of issues that the court had to deal with, allowing the focus to be properly on the areas of disagreement between them. The experts also found the conferences valuable, saying that the joint reports accurately reflected the expert views and that it allowed them to better understand reasoning of the other experts through robust and technical discussions about the evidence. The experience in the proceeding is testament to the benefits of expert conferences.

This does not mean that the participants were completely satisfied with the way the Court managed the conferences. It is clear that splitting up experts into different areas of science can be challenging to get right, particularly where there are experts with different kinds of expertise over the same issue - such as the failure of a conductor. It is something the Court has to figure out based on the nature of the expert evidence and the facts of the case. The most substantive critique of the Court's approach was that it failed to adequately consult the parties when the work of one of the expert conferences indicated that further testing was required. This is a fair point: if there is going to be the delay and cost that extra testing entails, the starting point should be that the parties be given the opportunity to make submissions on whether it is justified.

The involvement of Associate Justice Zammit as moderator in the larger conferences appears to have been very helpful, even essential. Indeed, it is easy to see how difficulties could arise with so many people in one room without someone independent and experienced to manage the discussion. However, the moderator must ensure that they do not use their position to push experts into agreement where there is none.

The impact the personalities of the experts might have on the outcome of the conference did not greatly trouble the lawyers, but one expert, unsurprisingly, noted some friction during the conferences. He also made it clear that the experts became somewhat adversarial and positional

177 Interview with expert B above n 73. 
when the moderator was absent. Care should be taken that the experts do not misunderstand their role within the conference, and feel able to resist compromise and stick to their position where they think it is the best view of the evidence. The Court could address this by providing more information and perhaps even training to the experts prior to the commencement of the conferences. In addition, the court and the parties should remember that experts do not usually have legal training, and so do not think and write like lawyers. This problem will be particularly acute where the experts do not have any experience in giving evidence to a court. The Court should do more to prepare the experts for the expert conferences, perhaps having a training session prior to the commencement of the conference, and developing resources to assist them understand their role in the process.

The comments of the experts show that the process forced upon them by the court is not necessarily one that leads to the best scientific outcome. They noted the limitations of bringing experts together after experimentation, particularly where the experiments were on the cutting edge of scientific knowledge. However, it is difficult to see how the experts could be brought together to conduct experiments at the beginning of the proceeding - but where possible, it should be considered.

Overall, the expert conferences in the Kilmore East bushfire proceeding were a success. The experience of the court and the participants shows that it is a useful procedure for courts, particularly where the evidence is as complex as it was in this case. All participants said that it substantially reduced the expert material that the court had to deal with during the trial. While care should always be taken to ensure that the process is just, effective and does not distort the evidence that ends up before the court, it is a powerful tool for courts dealing with complex expert evidence. 


\section{APPENDIX}

\section{A. Section one: view from Victorian bench}

In the process of preparing for the interviews with the participants in the Kilmore East bushfire proceeding, a number of judges not involved in the Kilmore East Bushfire proceedings were asked to comment generally on expert conferences, with a particular focus on the issues that came up in Kilmore East bushfire proceeding. This included their thoughts on managing the expert evidence in such a large case, the value of quarantining of experts from the parties during the expert conferences, and the role of the judicial moderator. There was considerable diversity of opinion.

\section{General comments on expert conferences}

All of the judges interviewed acknowledged that expert conferences were a useful tool for the court in some cases. There was, however, significant disagreement about the extent to which they should be used. As will be seen, some judges said expert conferences should always be used when you have multiple experts giving evidence on the same area; others thought that it was only useful for large trials or particularly complex evidence. All pointed out that the appropriate approach depends on the facts of the case before the Court.

Justice Beach said that for cases of the scale of the Kilmore East Bushfire proceeding, expert conferences were a powerful tool to handle the expert evidence:

I can't imagine in a case as complex as the recent bushfire case, with so many areas of expertise, how it might sensibly have been conducted if you had eight months of plaintiff's experts, one after the other, on different topics, just getting one side, one side, one side, and then suddenly eight months' later the plaintiff closes the case and the defendants start calling people who say the exact opposite. I can't imagine how burdensome that might be to a trial judge. Clearly [the expert conferences] worked very well. 178

Justice Almond was positive about the potential value of expert conferences, saying that in the "best case" they could resolve the case by removing issues from dispute, or narrowing and confining the issues, revealing what is "truly in dispute". ${ }^{179}$ Justice Hargrave said that it "stops experts being infected by their instructions" and "trying to put something which is pushing the

178 Interview with Justice Beach (2 September 2014, Supreme Court of Victoria, Melbourne).

${ }^{179}$ Interview with Justice Almond (13 October 2014, Supreme Court of Victoria, Melbourne). 
boundaries" because they know they will be accountable to their colleagues in the conference. ${ }^{180}$ He said expert conferences also have the potential to "drill down to what the real difference" between the experts is, and thereby reducing the work of the judge.181 Furthermore, he said that the joint reports were often essential in saving judges' time:

Judges can waste a lot of time reading very detailed expert reports which appear to different but in the end there is only a few things standing between them. In most cases, judges shouldn't have to bother with the individual reports. The joint report which comes up following the conclave should be all the judge needs to be taken to, unless someone refers to the individual report (if there is one) during the course of examination. ${ }^{182}$

Justice Beach and Justice Almond were careful to point out some of the limitations of the procedure. Justice Almond said that expert conferences were not a failsafe way of managing expert evidence:

If the experts aren't truly engaged in the process of exchange and open listening and are unable to refrain from being too positional, then the process can work fairly poorly and end up blurring the lines and entrenching the conflict between the parties. I have had cases where the joint engagement between experts in conclaves or at trial is reduced to two individuals grating against each other and getting annoyed. ${ }^{183}$

Justice Beach said the benefits of the traditional method of managing experts should not be discounted. ${ }^{184}$ He was concerned that conferences could allow the personalities of some experts to impact on the way the case is determined, rather than having their evidence tested in court. He also warned that in small cases expert conferences could prove costly to the parties but not achieve any real benefit over having the experts give evidence in the traditional way. ${ }^{185} \mathrm{He}$ emphasised that the judge should consider whether it will actually be helpful:

Just think why you're doing it and what are the real benefits and, if there aren't, the way we've been running cases before conclaves, it's developed over hundreds of years by very clever people, it works very well. Just be a bit careful, that's what I'd say. ${ }^{186}$

\footnotetext{
${ }^{180}$ Interview with Justice Hargrave (6 October 2014, Supreme Court of Victoria, Melbourne).

181 Ibid.

182 Ibid.

183 Interview with Justice Almond (13 October 2014, Supreme Court of Victoria, Melbourne).

184 Interview with Justice Beach (2 September 2014, Supreme Court of Victoria, Melbourne).

185 Ibid.

186 Ibid.
} 
It is clear from the comments of the judges that expert conferences are a useful tool, particularly in cases as large as the Kilmore East bushfire proceeding. All acknowledged their effectiveness in some situations. However, their comments identify some risks involved in expert conferences, and there will be occasions where the more traditional approach will work better.

\section{Quarantining of experts}

Justice Hargrave said that he always orders that the parties have "nothing to do" with the experts once the expert conferences have commenced, and only permits communication to the experts signed by both parties. ${ }^{187}$ He said he takes this approach because he has seen examples of the parties or their lawyers seeking to influence experts to take certain positions. ${ }^{188}$ This is the standard order in the Commercial Court, and it recognises that the experts are officers of the Court rather than representatives of the parties. ${ }^{189}$

\section{Need for independent chair or moderator in conferences}

Justice Hargrave, Justice Croft and Justice Almond were supportive of using independent chairs or moderators in at least some expert conferences. Justice Hargrave said that having a court appointed moderator was valuable:

[...] especially in very large litigation where the conclave may go for days and so on, I think having an Associate Justice or a Judicial Registrar involved would be good to put the experts on the right page in interpreting the court's [instructions] or, where necessary, arranging to approach the Court for clarification. 190

Justice Croft said it would be necessary to "lay down the parameters for the conclaves fairly carefully" to ensure the process was effective. ${ }^{191}$ He went on to say that determining whether to appoint a mediator to the conclave depended on the size of the case, and whether the experts had experience in providing evidence to the Court, and their personalities. ${ }^{192}$

Justice Almond said that some judicial intervention was desirable in running expert conferences to "formalise the process" and ensure the experts were kept on track. ${ }^{193}$ He said it would sometimes

\footnotetext{
187 Interview with Justice Hargrave (6 October 2014, Supreme Court of Victoria, Melbourne).

188 Ibid.

189 Ibid.

190 Ibid.

${ }^{191}$ Interview with Justice Croft (14 October 2014, Supreme Court of Victoria, Melbourne).

192 Ibid.

193 Interview with Justice Almond (13 October 2014, Supreme Court of Victoria, Melbourne).
} 
be preferable to have a neutral person chairing expert conferences, and if it were a "highly contested matter" he would consider using an associate judge. ${ }^{194}$

\section{B. Section Two: Methodology}

The primary source of material for this research project was gathered in interviews with judges of the Supreme Court of Victoria and some of the participants of the Kilmore East bushfires proceeding. The interviews were conducted in late 2014 and early 2015 in person and by email. The judges selected were either involved in the proceeding (Justice Forrest) or were chosen as they represented a range of different views about the management of expert evidence (Justice Beach, Justice Croft, Justice Almond and Justice Hargrave). The participants from the Kilmore East bushfire proceeding interviewed were selected to ensure that the research took account of both the plaintiff and defendant sides, as well as covering the different roles within the proceeding. To this end, two barristers, two solicitors and two experts were interviewed. They agreed to be interviewed on the basis that they would remain anonymous due to the sensitive nature of some of their comments, and so all identifying information has been removed from their answers.

Interviews in person were semi-structured and the questions were both broad ("Did expert participation in expert conferences and production of joint reports improve the effectiveness and justice of the proceedings?") and more focussed ("Did you have to provide [the experts] with any guidance as to what to expect [in the expert conferences]?"). Interviews conducted by email or letter were by response to questions provided to the interviewees. The research project has some obvious limitations: it was not possible to interview all the judges of the Supreme Court or all the participants in the Kilmore East bushfire proceeding. It does not in any way assess the experience of the many plaintiffs, whose tragic experiences were the basis of the case. This paper is not intended to be a source of comprehensive empirical data, but rather to ensure the experience of the Court is recorded and that any lessons that were learnt during the proceeding are captured for posterity. It is hoped that this record will be of value to other judges of the Supreme Court of Victoria, as well as in other jurisdictions, and to legal practitioners. One of the aims of the project was to better understand how newer methods of managing expert evidence were used by the court and perceived by those who were using them - and the Kilmore East bushfire proceeding was a good opportunity to assess some of these issues.

194 Ibid. 


\section{University Library}

\section{- M M I E R R V A gateway to Melbourne's research publications}

Minerva Access is the Institutional Repository of The University of Melbourne

Author/s:

McKenzie, S

Title:

Expert Conferences in the Kilmore East bushfire proceeding

Date:

2016-04-13

Citation:

McKenzie, S. (2016). Expert Conferences in the Kilmore East bushfire proceeding. Supreme Court of Victoria.

Persistent Link:

http://hdl.handle.net/11343/91567 